\title{
Prognostic significance of histological invasion in high grade soft tissue sarcomas
}

\author{
Satoshi Tsukushi", Yoshihiro Nishida, Hiroshi Urakawa, Eiji Kozawa and Naoki Ishiguro
}

\begin{abstract}
High grade soft tissue sarcomas often show histological invasion to adjacent compartment including bone and vessel. This study aimed to evaluate histological invasion in high grade soft tissue sarcomas, clarify its impact on prognosis and devise treatment strategies. We retrospectively reviewed 133 patients with non-small round cell high grade soft tissue sarcomas surgically treated between 2001 and 2011. Clinical and histological factors examined for prognostic value included age, gender, size, depth, location, adjuvant therapy and invasion to adjacent compartment. Study endpoints included overall survival rate, event free survival rate and local recurrence free survival rate, estimated by the Kaplan-Meier method. Univariate and multivariate analyses were performed using the log-rank test and Cox proportional hazards model. Local recurrence was recognized in 14 cases (11\%). The 5-year overall survival rate and 5-year event free survival rate were $82.2 \%$ and $63.6 \%$ respectively. The metastasis-free survival rate at 5 years and local recurrence-free survival rate at 5 years were $69.8 \%$ and $86.8 \%$ respectively. Histological invasion to adjacent compartment was noted in 52 cases (39\%), and was significantly correlated with histological type ( $p=0.01)$, tumor size $(p=0.009)$, and depth $(p<0.05)$. In multivariate analyses, we showed that tumor size and histological invasion were significant independent predictors of OS (hazard ratio 8.1/2.5) and EFS (hazard ratio 5.5/2.2), while only tumor size was a significant independent predictor of LRFS (hazard ratio 4.0). We evaluated the relation between histological invasion and the oncological outcomes of high grade soft tissue sarcomas. In multivariate analyses, histological invasion was found to be an independent adverse prognostic factor with hazard ratios of 2.2-2.5, suggesting that a detailed assessment of these factors is essential. Histological invasion showed a correlation with tumor size and histological type, and the surgical margin should be decided based on these factors.
\end{abstract}

Keywords: Soft tissue sarcoma; Histological invasion; Prognosis; Clinical outcome

\section{Introduction}

Soft tissue sarcoma is an uncommon cancer with variable histological subtypes and clinical behaviors. Once metastases develop most patients die of their disease. Numerous studies have identified clinical prognostic factors that could influence survival and local recurrence of soft tissue sarcoma (Behranwala et al. 2004; Carneiro et al. 2011; Coindre et al. 1996; Collin et al. 1987; Eilber et al. 2004; Eilber et al. 2003; Gaynor et al. 1992; Heise et al. 1986; Kattan et al. 2002; Lahat et al. 2008; McKee et al. 2004; Mutter et al. 2012; Pisters et al. 1996; Ramanathan et al. 1999; Riad et al. 2004; Rööser et al. 1988; Singer et al. 1994; Stefanovski et al. 2002; Stojadinovic et al. 2002; Stotter et al. 1990; Trojani et al. 1984; Ueda et al. 1988; Zagars et al.

\footnotetext{
* Correspondence: s-tsuku@med.nagoya-u.ac.jp

Department of Orthopaedic Surgery, Nagoya University Graduate School of Medicine, 65 Tsurumai-cho, Showa-ku, Nagoya 466-8550, Japan
}

2003). It would be beneficial for clinical management and research to identify these factors. However soft tissue sarcomas represent a heterogeneous group of rare malignant tumors with a wide spectrum of histological grade. There are few large studies that have focused on high grade sarcomas. Most of soft tissue sarcomas characteristically show histological invasion to adjacent tissues. This makes local control more difficult, and may necessitate wide resection including adequate amounts of normal tissue. Especially high grade sarcomas, often extend beyond their compartment of origin, invading adjacent compartments, and showing microscopic invasion to bone and neurovascular bundles. These features may not only complicate or preclude limb-preserving surgery but also provide distant metastasis in the early period, markedly worsening the prognosis (Ferguson et al. 2006; Merimsky et al. 1998; LeVay et al.

\section{实}


1993). It is therefore important to recognize to what extent this kind of histological invasion is detected in high grade sarcomas, and what influence it exerts on survival and local recurrence.

This study was undertaken to assess histological invasion of high grade sarcomas to adjacent compartments, define its influence on prognosis, and suggest more suitable therapeutic strategies on the basis of the results obtained.

\section{Materials and methods}

The prospectively collected database was retroepectively reviewed to identify all patient with non metastatic non-small round cell soft tissue sarcomas surgically treated between 2001 and 2011 in our institution. We identified 183 patients with non-small round cell soft tissue sarcomas. We excludes 50 low grade sarcomas (20 dermatofibrosarcoma protuberans, 13 well differentiated liposarcomas, 7 solitary fibrous tumors, 6 low grade fibromyxoid sarcomas and 4 low grade fibrosarcoma). The remaining 133 patients (78 males, 55 females) were studied. Clinical and histological factors examined for prognostic value included age, gender, size, depth, location, adjuvant therapy and invasion to adjacent compartments. Study endpoints included overall survival rate (OS), event free survival rate (EFS) and local recurrence free survival rate (LRFS), estimated by the Kaplan-Meier method. Univariate and multivariate analyses were performed using the log-rank test and Cox proportional hazards model.

In all cases histological invasion to adjacent compartments was evaluated in detail in resected specimens, and classified as follows: (1) extra-compartmental invasion by intramuscular or intermuscular tumor destroying the adjacent fascia; (2) superficial tumor destroying the deep level of the fascia and invading the deep level of the muscle; (3) tumor destroying the adjacent periosteum or bone; (4) invasion of adjacent vascular sheaths or nerve sheaths.

Tumor size was measured on preoperative images obtained by MRI and other imaging modalities. Tumors were initially classified histologically into low or high grade according to the classification of Broders et al. (Grades 1 and 2 as low and grades 3-4 as high grade) and in recent years according to the French Federation classification (FNCLCC) (grade1 as low grade and grades 2 and 3 as high grade).

Tumor size was measured on preoperative MRI and other images. Histopathological measurements were made in cases resected at the prereferral hospital. The patients' clinicopathological data are listed in Table 1.

In the case of soft tissue sarcomas we aim for a wide resection securing a $3 \mathrm{~cm}$ margin from the tumor edge. In cases subjected to an unplanned excision we undertake definitive surgery within 2 months of the unplanned procedure to secure a $3 \mathrm{~cm}$ margin from the site of the previous surgical manipulations. In all cases a detailed postoperative histological assessment was made of the resected specimen. Resections were defined as R2 if the margins were macroscopically positive, $\mathrm{R} 1$ if all macroscopic disease was removed but with the margins microscopically positive, or R0 if margins were microscopically negative. Postoperative radiotherapy was administered to selected cases of R0 with a close margin, R1and R2.

All patients were followed by physical examination at every visit to detect any local recurrence, MRI of the primary site every 6 months, and CT of the chest after surgical treatment every 3 months until 2 years after surgery and every 6 months thereafter.

Age ranged from 8 to 91 years (mean 62 years), The minimum duration of follow-up was 12 months (mean, 51 months; range $12 \sim 134$ months). Site of origin was the upper extremities in 23 cases, lower extremities in 85 , and trunk in 25. Tumor localization was superficial in 62 cases, and deep in 71. The pathological diagnosis was undifferentiated pleomorphic sarcoma in 52 cases, liposarcoma in 23, myxofibrosarcoma in 14, malignant peripheral nerve sheath tumor in 14, synovial sarcoma in 13 , leiomyosarcoma in 10, and other types in 7 .

\section{Statistical analyses}

Survival was estimated by the Kaplan-Meier method. OS, EFS and LRFS were compared with the log-rank test. The multivariate analysis was performed using a Cox proportional hazard model. The variables included in the multivariate analysis were the significant factors identified in the univariate analysis. The risk factor of histological invasion was assessed using Fisher's exact test or the Chi-square test. In all statistical analyses, $\mathrm{p}<0.05$ was considered to be significant. Statistical analysis was performed using SPSS Version 21.0 (SPSS Inc, Chicago, IL).

\section{Results}

The oncological outcome was continuous disease free in 82 cases, no evidence of disease in 18, alive with disease in 8 , dead of disease in 22 , and dead of other disease in 3. Local recurrence was recognized in 14 cases $(11 \%)$. The 5 -year cumulative survival and 5-year disease-free survival rates were $82.2 \%$ and $63.6 \%$ respectively (Table 1 ). The metastasis-free survival rate at 5 years and local recurrence-free survival rate at 5 years were $69.8 \%$ and $86.8 \%$ respectively.

The overall survival rate at 5 years and the event free survival rate at 5 years in the cases without invasion were $90.3 \%$ and $77.5 \%$ respectively. On the other hand, in the cases with histological invasion to an adjacent compartment the overall survival rate at 5 years and the 
Table 1 Clinicopathological data for 133 patients with non-small round cell high grade soft tissue sarcomas

\begin{tabular}{|c|c|c|c|c|c|}
\hline Characteristics & $\begin{array}{c}\text { All } \\
(N=133)\end{array}$ & $\%$ & $\begin{array}{l}\text { With invasion } \\
\qquad(\mathrm{N}=52)\end{array}$ & $\begin{array}{l}\text { Without invasion } \\
\qquad(\mathrm{N}=\mathbf{8 1})\end{array}$ & P-value** \\
\hline \multicolumn{6}{|l|}{ Age } \\
\hline Median & $62 \mathrm{yr}$ & & & & \\
\hline$<60 \mathrm{yr}$ & 56 & 42 & 16 & 38 & \\
\hline$\geqq 60 \mathrm{yr}$ & 77 & 58 & 36 & 43 & $p=0.064$ \\
\hline \multicolumn{6}{|l|}{ Gender } \\
\hline Male & 78 & 59 & 32 & 46 & $p=0.587$ \\
\hline Female & 55 & 41 & 20 & 35 & \\
\hline \multicolumn{6}{|l|}{ Tumor location } \\
\hline Upper extremity & 23 & 17 & 11 & 12 & \\
\hline Lower extremity & 85 & 64 & 28 & 56 & \\
\hline Trunk & 25 & 19 & 13 & 12 & $p=0.142$ \\
\hline \multicolumn{6}{|l|}{ Tumor depth } \\
\hline Superficial & 62 & 47 & 13 & 49 & \\
\hline Deep & 71 & 53 & 39 & 32 & $p<0.05$ \\
\hline \multicolumn{6}{|l|}{ Tumor size } \\
\hline$\leqq 5 \mathrm{~cm}$ & 46 & 35 & 11 & 35 & \\
\hline$>5 \mathrm{~cm}$ & 87 & 65 & 41 & 46 & $p=0.009$ \\
\hline \multicolumn{6}{|l|}{ Surgical margin } \\
\hline RO & 122 & 92 & 39 & 74 & \\
\hline R1 & 11 & 8 & 13 & 7 & $p<0.05$ \\
\hline R2 & 0 & 0 & 0 & 0 & \\
\hline \multicolumn{6}{|l|}{ Histological diagnosis } \\
\hline Undifferentiated pleomorphic sarcoma & 52 & 39 & 31 & 21 & $p=0.01$ \\
\hline Liposarcoma & 23 & 17 & 4 & 19 & \\
\hline Myxofibrosarcoma & 14 & 11 & 3 & 11 & \\
\hline MPNST* & 14 & 11 & 5 & 9 & \\
\hline Synovial sarcoma & 13 & 10 & 4 & 9 & \\
\hline Leiomyosarcoma & 10 & 8 & 3 & 7 & \\
\hline Other & 7 & 5 & 2 & 5 & \\
\hline Continuously free of disease & 82 & 62 & 22 & 60 & \\
\hline Alive with disease & 8 & 6 & 4 & 4 & \\
\hline Alive and currently no evidence of disease & 18 & 14 & 10 & 8 & \\
\hline Dead of disease & 22 & 17 & 14 & 8 & \\
\hline Dead of other disease & 3 & 2 & 2 & 1 & \\
\hline Overall survival rate at 5 years & $82.2 \%$ & & $69.6 \%$ & $90.3 \%$ & \\
\hline Event-free survival rate at 5 years & $63.6 \%$ & & $41.3 \%$ & $77.5 \%$ & \\
\hline Metastasis-free survival rate at 5 years & $69.8 \%$ & & $53.0 \%$ & $80.8 \%$ & \\
\hline Local recurrence-free rate at 5 years & $86.8 \%$ & & $77.8 \%$ & $92.1 \%$ & \\
\hline
\end{tabular}

*MPNST; malignant peripheral nerve sheath tumor.

**The risk factor of invasion was assessed using Fisher's exact test or the Chi-square test.

event free survival rate at 5 years were much lower at $69.6 \%$ and $41.3 \%$ respectively.

After definitive surgery, 122 patients (92\%) had R0 margins and 11 (8\%) R1 margins. Thirty-two cases
(24\%) underwent postoperative radiotherapy. Chemotherapy at the time of the initial treatment was administered to 28 cases $(21 \%)$ including 13 of synovial sarcoma. 
In the univariate analysis size $(\mathrm{p}<0.001)$, depth $(\mathrm{p}<0.001)$ and histological invasion $(\mathrm{p}=0.01)$ were significant unfavorable prognostic factors for overall survival. (Figure 1) Size $(\mathrm{p}<0.001)$, depth $(\mathrm{p}<0.001)$ and histological invasion $(\mathrm{p}<0.001)$ were significant unfavorable prognostic factors for event free survival. (Figure 2) Gender ( $<<0.05$ ), size $(\mathrm{p}<0.01)$, depth $(\mathrm{p}<0.01)$ and histological invasion $(\mathrm{p}=0.025)$ were significant unfavorable prognostic factors for local recurrence free survival. (Figure 3) Univariate analyses for prognostic factors are listed in Table 2.

In the multivariate analysis, size (hazard ratio 8.1) and histological invasion (hazard ratio 2.5) were the independent factors associated with overall survival. Size (hazard ratio 5.5) and histological invasion (hazard ratio 2.2) were the independent factors associated with event free survival, while size alone (hazard ratio 4.0) was associated with local recurrence free survival. Multivariate analyses for prognostic factors are listed in Table 3.

In 52 cases (39\%) histological invasion of an adjacent compartment was detected. Histological invasion was significantly associated with size $(\mathrm{p}=0.009)$, depth $(\mathrm{p}<0.05)$ and histological subtype (undifferentiated pleomorphic sarcoma: $\mathrm{p}=0.01)$ (Table 1$)$.

\section{Discussion}

Soft tissue sarcoma is an uncommon cancer with variable histological subtypes and clinical behaviors. Once metastases develop most patients die of their disease. Numerous studies have identified clinical prognostic factors that could influence survival and local recurrence of soft tissue sarcoma (Behranwala et al. 2004; Carneiro et al. 2011; Coindre et al. 1996; Collin et al. 1987; Eilber et al. 2004; Eilber et al. 2003; Gaynor et al. 1992; Heise et al. 1986; Kattan et al.
2002; Lahat et al. 2008; McKee et al. 2004; Mutter et al. 2012; Pisters et al. 1996; Ramanathan et al. 1999; Riad et al. 2004; Rööser et al. 1988; Singer et al. 1994; Stefanovski et al. 2002; Stojadinovic et al. 2002; Stotter et al. 1990; Trojani et al. 1984; Ueda et al. 1988; Zagars et al. 2003). Soft tissue sarcomas are characterized by aggressive histological invasiveness, which has been correlated with their prognosis (Gustafson et al. 2003; Carneiro et al. 2011). Almost all high grade sarcomas show histological extracapsular invasion. Meanwhile, myxofibrosarcomas whose local control is especially difficult because of aggressive invasiveness have been reported to develop significantly fewer distant metastases than leiomyosarcomas (Mutter et al. 2012). In the present subgroup analysis as well, although almost all myxofibrosarcomas showed an invasive growth pattern the prognosis was favorable provided that local control was achieved. On the other hand, the invasive growth patterns can be divided into two groups. One is the intra-compartmental invasion limited to within the compartment of tumor origin which is frequently observed in myxofibrosarcomas. The other is the extra-compartmental invasion which extends beyond the compartment to involve an adjacent compartment. The latter in our experience often assume a more aggressive clinical course. This prompted us to undertake the present study to determine whether cases with this kind of histological extracompartmental invasion show differences in metastases, survival, and local recurrence as compared with those without it. In high grade sarcomas, histological invasion to adjacent compartments was found to be a significantly unfavorable prognostic factor as compared to the absence of invasion with regard to overall survival, event free survival, and local recurrence free

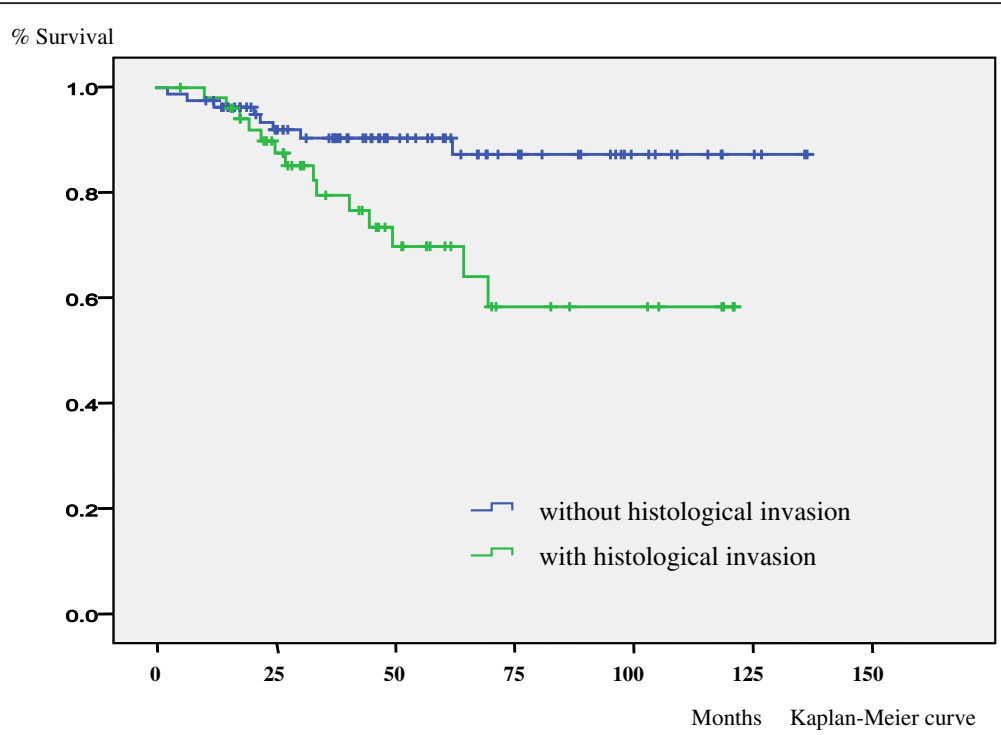

Figure 1 Kaplan-Meier life table analysis of overall survival of high grade soft tissue sarcoma patients with or without histological invasion. For overall survival histological invasion $(p=0.01)$ was a significant unfavorable prognostic factor. 


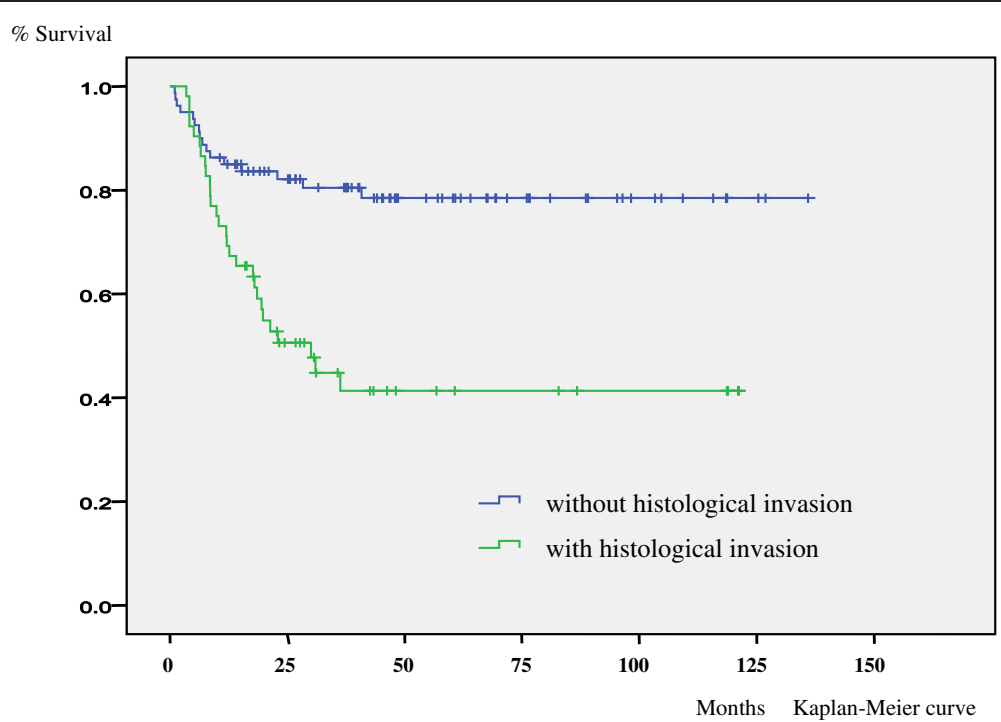

Figure 2 Kaplan-Meier life table analysis of event free survival of high grade soft tissue sarcoma patients with or without histological invasion. For event free survival histological invasion $(p<0.001)$ was a significant unfavorable prognostic factor.

survival. In the multivariate analysis as well, in addition to size, histological invasion was noted to be an independent unfavorable prognostic factor for both overall survival and event free survival.

With extensive discussion between surgeons and pathologists, as many sections as possible are evaluated. However, it may still be very difficult to fully evaluate the invasion status particularly in larger specimens. For this reason, our study is thus limited by the fact that microscopic invasion may have been overlooked to some extent by pathology. The prognosis of deep soft tissue sarcomas showing histological invasion of bone and vascular bundles has been reported to be poor (Ferguson et al. 2006; Merimsky et al. 1998; LeVay et al. 1993). This means that these tumors have a propensity to show histological invasion beyond their compartment of origin. Considering the present results in which histological invasion was demonstrated to exert an adverse influence on prognosis, more detailed and accurate histological assessment will be required to devise more appropriate therapeutic strategies. For high grade sarcomas, the establishment of new stratified therapies taking into account this factor is urgently needed.

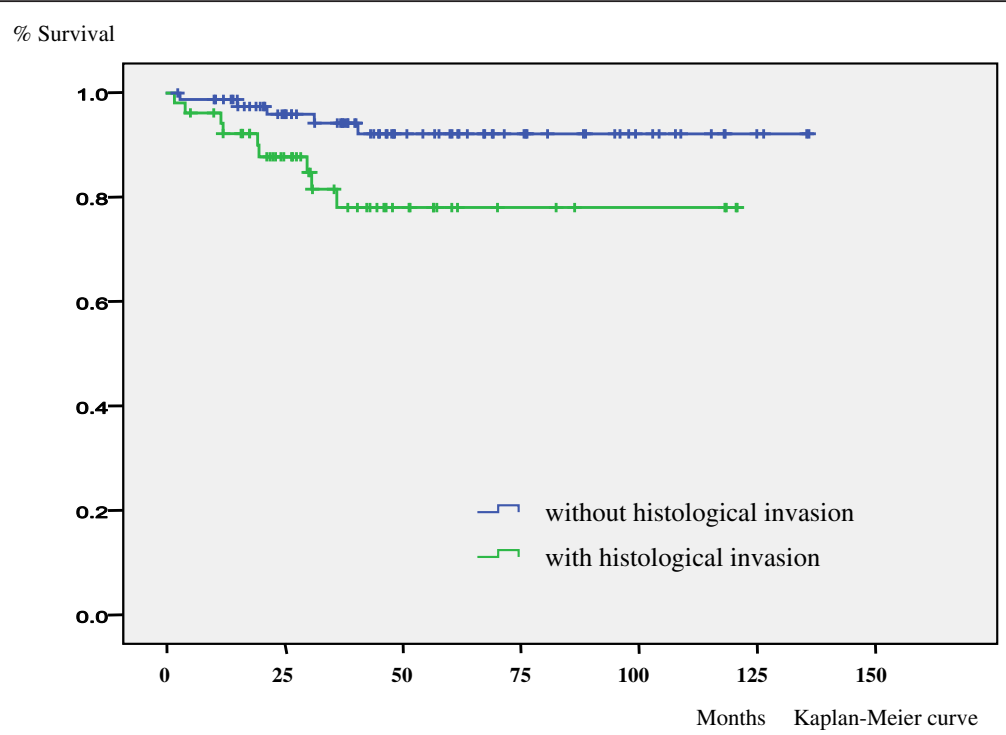

Figure 3 Kaplan-Meier life table analysis of local recurrence free survival of high grade soft tissue sarcoma patients with or without histological invasion. For local recurrence free survival histological invasion $(p=0.025)$ was a significant unfavorable prognostic factor. 
Table 2 Univariate analysis for prognostic factors in overall survival, event free survival and local recurrence free survival

\begin{tabular}{|c|c|c|c|c|c|c|c|}
\hline Factors & No. of patients & $\begin{array}{l}\text { Overall 5-year } \\
\text { survival rate }\end{array}$ & P-value & $\begin{array}{l}\text { Event free } 5 \text {-year } \\
\text { survival rate }\end{array}$ & P-value & $\begin{array}{l}\text { Local recurrence free } \\
5 \text {-year survival rate }\end{array}$ & P-value \\
\hline \multicolumn{8}{|l|}{ Age } \\
\hline$\geqq 60 \mathrm{yr}$ & 56 & $80.8 \%$ & $p=0.298$ & $64.4 \%$ & $p=0.711$ & $87.0 \%$ & $p=0.926$ \\
\hline$<60 \mathrm{yr}$ & 77 & $84.5 \%$ & & $62.0 \%$ & & $86.5 \%$ & \\
\hline \multicolumn{8}{|l|}{ Gender } \\
\hline Male & 78 & $78.7 \%$ & $p=0.362$ & $55.4 \%$ & $p=0.067$ & $96.3 \%$ & $p=0.040 *$ \\
\hline Female & 55 & $86.9 \%$ & & $75.8 \%$ & & $80.5 \%$ & \\
\hline \multicolumn{8}{|c|}{ Tumor location } \\
\hline Extremity & 108 & $83.4 \%$ & $p=0.271$ & $64.9 \%$ & $p=0.874$ & $89.7 \%$ & $p=0.075$ \\
\hline Trunk & 25 & $76.6 \%$ & & $58.3 \%$ & & $74.4 \%$ & \\
\hline \multicolumn{8}{|l|}{ Tumor depth } \\
\hline Superficial & 62 & $94.2 \%$ & $p<0.001^{*}$ & $82.3 \%$ & $p<0.001^{*}$ & $95.7 \%$ & $p<0.01^{*}$ \\
\hline Deep & 71 & $71.0 \%$ & & $45.7 \%$ & & $77.4 \%$ & \\
\hline \multicolumn{8}{|l|}{ Tumor size } \\
\hline$\leqq 5 \mathrm{~cm}$ & 46 & $100.0 \%$ & $p<0.001^{*}$ & $90.8 \%$ & $p<0.001^{*}$ & $100.0 \%$ & $p<0.01^{*}$ \\
\hline$>5 \mathrm{~cm}$ & 87 & $71.6 \%$ & & $48.1 \%$ & & $78.1 \%$ & \\
\hline \multicolumn{8}{|c|}{ Histological invasion } \\
\hline Yes & 52 & $69.6 \%$ & $p=0.01^{*}$ & $41.3 \%$ & $p<0.001^{*}$ & $77.8 \%$ & $p=0.025^{*}$ \\
\hline No & 81 & $90.3 \%$ & & $77.5 \%$ & & $92.1 \%$ & \\
\hline \multicolumn{8}{|c|}{ Adjuvant radiotherapy } \\
\hline Yes & 32 & $76.5 \%$ & $p=0.964$ & $57.1 \%$ & $p=0.538$ & $78.7 \%$ & $p=0.128$ \\
\hline No & 101 & $84.7 \%$ & & $66.1 \%$ & & $90.1 \%$ & \\
\hline \multicolumn{8}{|c|}{ Adjuvant chemotherapy } \\
\hline Yes & 28 & $88.0 \%$ & $p=0.596$ & $66.2 \%$ & $p=0.952$ & $91.8 \%$ & $p=0.625$ \\
\hline No & 105 & $81.3 \%$ & & $63.4 \%$ & & $86.0 \%$ & \\
\hline
\end{tabular}

*Statistically significant difference.

Table 3 Multivariate cox proportional analysis for prognostic factors in overall survival, event free survival and local recurrence free survival

\begin{tabular}{|c|c|c|c|c|c|c|}
\hline \multirow[t]{2}{*}{ Factors } & \multicolumn{2}{|c|}{ Overall survival } & \multicolumn{2}{|c|}{ Event free survival } & \multicolumn{2}{|c|}{ Local recurrence free survival } \\
\hline & Hazard ratio $(95 \% \mathrm{Cl})$ & P-value & Hazard ratio $(95 \% \mathrm{Cl})$ & P-value & Hazard ratio $(95 \% \mathrm{Cl})$ & P-value \\
\hline \multicolumn{7}{|l|}{ Age } \\
\hline$\geqq 60 \mathrm{yr}$ & & & & & 1 (referent) & 0.959 \\
\hline$<60 \mathrm{yr}$ & & & & & $1.0(0.33-2.79)$ & \\
\hline \multicolumn{7}{|l|}{ Tumor depth } \\
\hline Superficial & 1 (referent) & 0.961 & 1 (referent) & 0.228 & 1 (referent) & 0.863 \\
\hline Deep & $1.0(0.39-2.35)$ & & $1.5(0.78-2.81)$ & & $1.1(0.35-3.47)$ & \\
\hline \multicolumn{7}{|l|}{ Tumor size } \\
\hline$\leqq 5 \mathrm{~cm}$ & 1 (referent) & $0.015^{*}$ & 1 (referent) & $0.002^{*}$ & 1 (referent) & $0.006^{*}$ \\
\hline$>5 \mathrm{~cm}$ & $8.1(2.46-26.42)$ & & $5.5(1.90-15.75)$ & & $4.0(1.38-10.13)$ & \\
\hline \multicolumn{7}{|c|}{ Histological invasion } \\
\hline No & 1 (referent) & $0.036^{*}$ & 1 (referent) & $0.012^{*}$ & 1 (referent) & 0.08 \\
\hline Yes & $2.5(1.35-4.71)$ & & $2.2(1.19-4.16)$ & & $1.8(1.11-3.15)$ & \\
\hline
\end{tabular}

*Statistically significant difference. 
In the multivariate analysis in this study, invasion did not reach significance as an independent unfavorable prognostic factor for local recurrence-free survival, although our experience suggests that in cases showing invasion the local recurrence rate is high. Wide resection of a tumor limited to a single compartment is technically relatively simple, whereas once a tumor extends beyond its compartment of origin it becomes technically demanding to achieve a wide resection with adequate margin. The results of the present prognostically unfavorable cases may have been biased by the inclusion of cases in which there was a competition between local recurrence and death. We thereby might underestimate the local recurrence rate. Histological invasion was significantly correlated with larger size $(\mathrm{p}=0.009)$, deep location $(\mathrm{p}<0.05)$ and undifferentiated pleomorphic sarcoma histological subtype $(\mathrm{p}=0.01)$. For cases with such factors we recommend that more aggressive surgery be provided and that the indications for adjuvant radiotherapy be liberally expanded.

In conclusion, high grade soft tissue sarcomas often show an extra-compartmental invasive growth pattern with involvement of bone, blood vessels, and other structures. This not only makes local control much more difficult to achieve, but in the present multivariate analysis was demonstrated to be an independent unfavorable prognostic factor for both overall survival and event free survival. Further investigations to evaluate invasiveness that cannot be evaluated by the histological grade alone and to apply stratified therapy based on the obtained results are needed.

\section{Competing interest}

The authors declare that they have no competing interest.

\begin{abstract}
Authors' contributions
ST has made substantial contributions to conception and design, preparation and analysis of data and drafted the manuscript. YN designed the study. $\mathrm{HU}$, EK contributed to the draft and figures of the manuscript. NI conceived of the study and participated in its design and coordination. All authors read and approved the final manuscript.
\end{abstract}

Received: 30 May 2014 Accepted: 16 September 2014

Published: 22 September 2014

\section{References}

Behranwala KA, A'Hern R, Omar AM, Thomas JM (2004) Prognosis of lymph node metastasis in soft tissue sarcoma. Ann Surg Oncol 11:714-719

Carneiro A, Bendahl PO, Engellau J, Domanski HA, Fletcher CD, Rissler P, Rydholm A, Nilbert M (2011) A prognostic model for soft tissue sarcoma of the extremities and trunk wall based on size, vascular invasion, necrosis, and growth pattern. Cancer 117:1279-1287

Coindre JM, Terrier P, Bui NB, Bonichon F, Collin F, Le Doussal V, Mandard AM, Vilain MO, Jacquemier J, Duplay H, Sastre X, Barlier C, Henry-Amar M, Macé-Lesech J, Contesso G (1996) Prognostic factors in adult patients with locally controlled soft tissue sarcoma. A study of 546 patients from the French Federation of Cancer Centers Sarcoma Group. J Clin Oncol 14:869-877

Collin C, Godbold J, Hajdu S, Brennan M (1987) Localized extremity soft tissue sarcoma: an analysis of factors affecting survival. Ann Surg Oncol 5:601-612

Eilber FC, Rosen G, Nelson SD, Selch M, Dorey F, Eckardt J, Eilber FR (2003) High-grade extremity soft tissue sarcomas: factors predictive of local recurrence and its effect on morbidity and mortality. Ann Surg 237:218-226
Eilber FC, Brennan MF, Eilber FR, Dry SM, Singer S, Kattan MW (2004) Validation of the postoperative nomogram for 12-year sarcoma-specific mortality. Cancer 101:2270-2275

Ferguson PC, Griffin AM, O'Sullivan B, Catton CN, Davis AM, Murji A, Bell RS, Wunder JS (2006) Bone invasion in extremity soft-tissue sarcoma: impact on disease outcomes. Cancer 106:2692-2700

Gaynor JJ, Tan CC, Casper ES, Collin CF, Friedrich C, Shiu M, Hajdu SI, Brennan MF (1992) Refinement of clinicopathologic staging for localized soft tissue sarcoma of the extremity: a study of 423 adults. J Clin Oncol 10:1317-1329

Gustafson P, Akerman M, Alvegård TA, Coindre JM, Fletcher CD, Rydholm A, Willén H (2003) Prognostic information in soft tissue sarcoma using tumour size, vascular invasion and microscopic tumour necrosis-the SIN-system. Eur J Cancer 39:1568-1576

Heise HW, Myers MH, Russell WO, Suit HD, Enzinger FM, Edmonson JH, Cohen J, Martin RG, Miller WT, Hajdu SI (1986) Recurrence-free survival time for surgically treated soft tissue sarcoma patients. Multivariate analysis of five prognostic factors. Cancer 57:172-177

Kattan MW, Leung DH, Brennan MF (2002) Postoperative nomogram or 12-year sarcoma-specific death. J Clin Oncol 20:791-796

Lahat G, Tuvin D, Wei C, Anaya DA, Bekele BN, Lazar AJ, Pisters PW, Lev D, Pollock RE (2008) New perspectives for staging and prognosis in soft tissue sarcoma. Ann Surg Oncol 15:2739-2748

LeVay J, O'Sullivan B, Catton C, Bell R, Fornasier V, Cummings B, Hao Y, Warr D, Quirt I (1993) Outcome and prognostic factors in soft tissue sarcoma in the adult. Int J Radiat Oncol Biol Phys 27:1091-1099

McKee MD, Liu DF, Brooks JJ, Gibbs JF, Driscoll DL, Kraybill WG (2004) The prognostic significance of margin width for extremity and trunk sarcoma. J Surg Oncol 85:68-76

Merimsky O, Isakov J, Kollender Y, Nirkin A, Inbar M, Meller I (1998) Vascular invasion in high grade sarcoma of the extremity is associated with short overall survival. Oncol Rep 5:985-989

Mutter RW, Singer S, Zhang Z, Brennan MF, Alektiar KM (2012) The enigma of myxofibrosarcoma of the extremity. Cancer 118:518-527

Pisters PW, Leung DH, Woodruff J, Shi W, Brennan MF (1996) Analysis of prognostic factors in 1,041 patients with localized soft tissue sarcomas of the extremities. J Clin Oncol 14:1679-1689

Ramanathan RC, A'Hern R, Fisher C, Thomas JM (1999) Modified staging system for extremity soft tissue sarcomas. Ann Surg Oncol 6:57-69

Riad S, Griffin AM, Liberman B, Blackstein ME, Catton CN, Kandel RA, O'Sullivan B, White LM, Bell RS, Ferguson PC, Wunder JS (2004) Lymph node metastasis in soft tissue sarcoma in an extremity. Clin Orthop Relat Res 426:129-134

Rööser B, Attewell R, Berg NO, Rydholm A (1988) Prognostication in soft tissue sarcoma. A model with four risk factors. Cancer 61:817-823

Singer S, Corson JM, Gonin R, Labow B, Eberlein TJ (1994) Prognostic factors predictive of survival and local recurrence for extremity soft tissue sarcoma. Ann Surg 219:165-173

Stefanovski PD, Bidoli E, De Paoli A, Buonadonna A, Boz G, Libra M, Morassut S, Rossi C, Carbone A, Frustaci S (2002) Prognostic factors in soft tissue sarcomas: a study of 395 patients. Eur J Surg Oncol 28:153-164

Stojadinovic A, Leung DH, Allen P, Lewis JJ, Jaques DP, Brennan MF (2002) Primary adult soft tissue sarcoma: time-dependent influence of prognostic variables. J Clin Oncol 20:4344-4352

Stotter AT, A'Hern RP, Fisher C, Mott AF, Fallowfield ME, Westbury G (1990) The influence of local recurrence of extremity soft tissue sarcoma on metastasis and survival. Cancer 65:1119-1129

Trojani M, Contesso G, Coindre JM, Rouesse J, Bui NB, De Mascarel A, Goussot JF, David M, Bonichon F, Lagarde C (1984) Soft-tissue sarcomas of adults; study of pathological prognostic variables and definition of a histopathological grading system. Int J Cancer 33:37-42

Ueda T, Aozasa K, Tsujimoto M, Hamada H, Hayashi H, Ono K, Matsumoto K (1988) Multivariate analysis for clinical prognostic factors in 163 patients with soft tissue sarcoma. Cancer 62:1444-1450

Zagars GK, Ballo MT, Pisters PW, Pollock RE, Patel SR, Benjamin RS, Evans HL (2003) Prognostic factors for patients with localized soft-tissue sarcoma treated with conservation surgery and radiation therapy: an analysis of 1225 patients. Cancer 97:2530-2543

\section{doi:10.1186/2193-1801-3-544}

Cite this article as: Tsukushi et al: Prognostic significance of histological invasion in high grade soft tissue sarcomas. SpringerPlus 2014 3:544. 